Research Article

\title{
Self-Nanoemulsifying Drug Delivery System (SNEDDS) for Oral Delivery of Cod Liver Oil
}

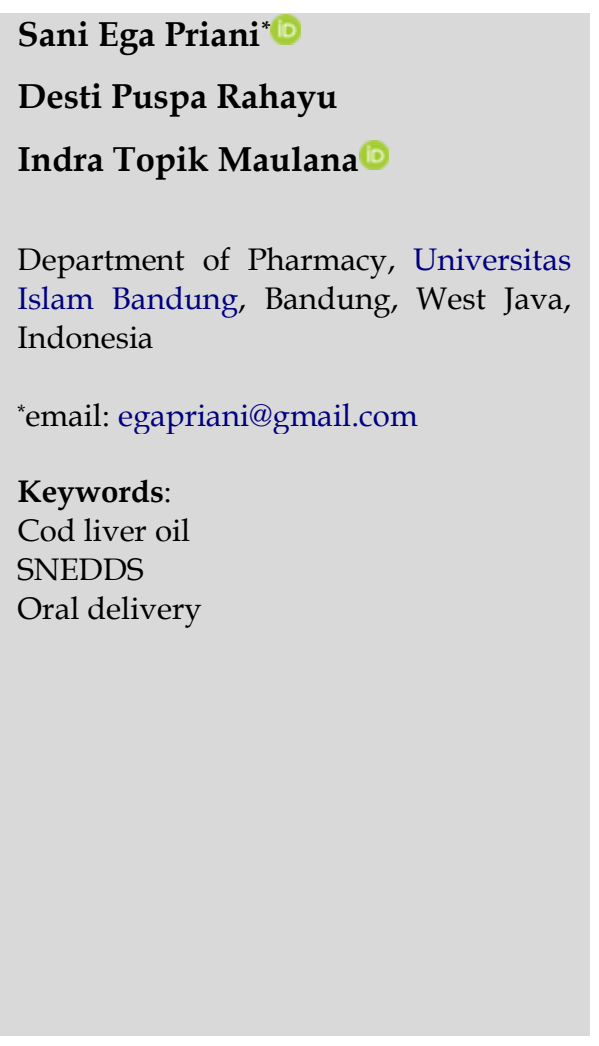

\begin{abstract}
Cod liver oil (CLO) has long been used as medicine or as a functional food. The CLO is a potential source of vitamin D, vitamin A, and omega fatty acids (eicosapentaenoic acid/EPA and docosahexaenoic acid/DHA). Self-nanoemulsifying drug delivery system (SNEDDS) can enhance dissolution, absorption, and bioavailability of hydrophilic and lipophilic substances for oral administration. The objective of this study was to develop a SNEDDS of CLO with good physical characteristics and stability. The optimization formula was carried out using various ratios of oil, surfactant, and cosurfactant. The physical properties of SNEDDS were determined by transmittance percentage, dispersibility, robustness, thermodynamics stability (heating-cooling cycle, centrifugation, and freeze-thaw cycle), and globule size distribution. The optimum formula of CLO-SNEDDS was obtained at a ratio of surfactant and cosurfactant $2: 1$ and a comparison of oil and surfactant mixtures $1: 6$. The CLO-SNEDDS meets the requirement of percent transmittance $(97.90 \pm 0.85)$, dispersibility (grade A), and stability based on robustness and thermodynamic stability tests. Diluted SNEDDS has an average globule size of $125 \mathrm{~nm}$ with a polydispersity index (PDI) of 0.515. CLO-SNEDDS preparation has good physical characteristics and stability.
\end{abstract}

Received: December 24th, 2020

Accepted: April 1st, 2021

Published: May 30th, 2021

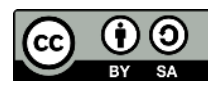

(C) 2021 Sani Ega Priani, Desti Puspa Rahayu, Indra Topik Maulana. Published by Institute for Research and Community Services Universitas Muhammadiyah Palangkaraya. This is an Open Access article under the CC-BYSA License (http://creativecommons.org/licenses/by-sa/4.0/). DOI: https://doi.org/10.33084/bjop.v4i2.1942

\section{INTRODUCTION}

Cod liver oil (CLO) is a food supplement extracted from the cod liver. Cod liver oil has long been used as medicine or as a functional food. Cod liver oil is a potential source of vitamin $\mathrm{D}$, vitamin $\mathrm{A}$, and omega fatty acids (eicosapentaenoic acid/EPA and docosahexaenoic acid/DHA)1. Cod liver oil can prevent heart disease by increasing the elasticity of blood vessels, lowering blood pressure, reducing lipid level, and increasing the HDL level ${ }^{24}$. Cod liver oil can support the treatment of type II diabetes mellitus (T2DM) by increasing insulin sensitivity ${ }^{5}$. Other studies have shown that CLO has cytotoxic, neuroprotective, hepatoprotective, anti-ulcer, and anti-inflammatory activities. Cod liver oil can also help brain development for children's growth ${ }^{6,7}$. In oral use, CLO is generally developed as an Emulsionbased delivery system. In the oil in a water emulsion system, CLO is in a dispersed form that is coated or protected by water 8 . The emulsion form of CLO is further modified into a nanoemulsion form ${ }^{10,11}$. The advantage of the nanoemulsion system is has a small globule size (nano-scale) and increasing its absorption and bioavailability ${ }^{12}$. However, the study that develops cod liver oil into another form of nanoemulsion system: The self-nanoemulsifying drug delivery system (SNEDDS), has not been carried out. 
In this study, CLO was developed in SNEDDS. The SNEDDS is a preconcentrated or anhydrous form of nanoemulsion, a mixture of oils, surfactants, and cosurfactants ${ }^{13}$. This system is expected to self-emulsify quickly in the aqueous stomach system and produces nano globules with a size of $20-200 \mathrm{~nm}$. The advantages of SNEDDS over nanoemulsion are enhancing the physical and chemical stability of the formulation and the ability to fill them into unit dosage forms, such as soft/hard capsules, which improves their commercial viability and patient compliance ${ }^{14}$.

Several studies have been carried out to develop SNEDDS for lipophilic active compounds. The results show that SNEDDS can increase the absorption and bioavailability of active compounds in oral delivery ${ }^{15,16}$. This study aimed to develop SNEDDS of CLO for oral delivery. Physical and stability evaluations were carried out to the preparations.

\section{MATERIALS AND METHODS}

\section{Materials}

The materials used in this study were COD (Lancida Hebar Technology), Cremophor ${ }^{\circledR R H}-40 \quad$ (BASF), polyethylene glycol (PEG) 400 (Bratachem), and monopotassium phosphate/KH2PO4 (Merck). The main instruments used in this study were gas chromatography-mass

spectrometry/GC-MS (Shimadzu GCMS-QP2010 Ultra), magnetic stirrer (Thermolyne S131120-33Q), particle size analyzer/PSA (Beckman Coulter), spectrophotometer UV-Vis (Shimadzu UV mini-1240), sonicator (Branson), analytical balance (Mettler Toledo AL204), dan vortex mixer (Thermo Scientific).

\section{Methods}

The research was carried out in several stages of the method as shown in Figure 1.

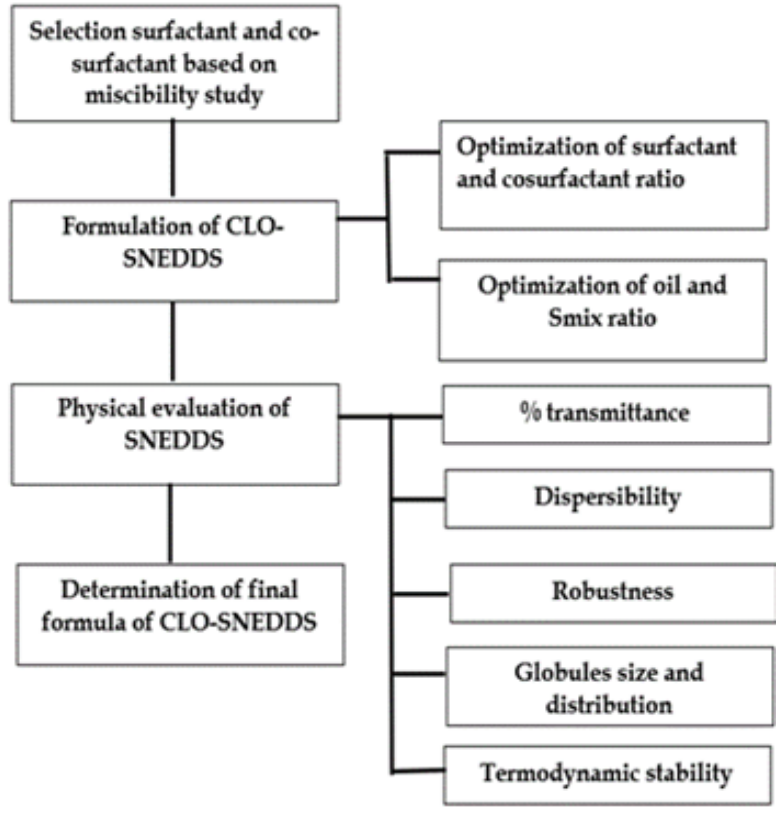

Figure 1. Research flow chart

\section{Miscibility study of oil and surfactant/co-surfactant}

The test was carried out by the miscibility study between CLO and surfactant/cosurfactant. The surfactants used were Cremophor ${ }^{\circledR R H}-40$ and Tween 80 ; the cosurfactant used was propylene glycol, Transcutol ${ }^{\circledR}$, and PEG 400. Miscibility studies were performed by preparing $1 \mathrm{~mL}$ of the CLO in a test tube then added with surfactant/cosurfactant until a clear mixture was obtained. Stirring and observation were provided every time addition of $1 \mathrm{~mL}$ of surfactant/cosurfactant ${ }^{17}$.

Optimization of surfactant and cosurfactant ratio for CLOSNEDDS

At this stage, the SNEDDS formula was optimized by varying the concentration of surfactants and cosurfactants at a ratio of oil and Smix (surfactant + cosurfactant) was $1: 9$. Comparison of surfactant and cosurfactant used was $3: 1 ; 2: 1$; and $3: 2$. The SNEDDS prepared by mixing oil, surfactant, and co-surfactant at a temperature of $40^{\circ} \mathrm{C}$, then stirred until homogeneous. The CLO-SNEDDS preparations were characterized by the percent transmittance test $\mathrm{t}^{18}$. 


\section{Physical evaluation of CLO-SNEDDS}

Percent transmittance - As much as $1 \mathrm{~mL}$ of eachSNEDDS preparation was diluted up to $100 \mathrm{~mL}$ using distilled water. Measurement was carried out at a wavelength of $650 \mathrm{~nm}$ using a UV-Vis spectrophotometer. Distilled water was used as blank ${ }^{19}$.

Dispersibility test - A dispersibility test was performed using a type II dissolution apparatus. As much as $1 \mathrm{~mL}$ of CLO-SNEDDS was added to the $250 \mathrm{~mL}$ of distilled water and stirred at $37 \pm 0.5^{\circ} \mathrm{C}$ at $50 \mathrm{RPM}$. Visual observation was carried out according to the emulsification grade, as shown in Table $\mathbf{I}^{17,20}$.

\begin{tabular}{|c|c|}
\hline Grade & Specification \\
\hline A & $\begin{array}{l}\text { Rapidly forming emulsion, with a clear or bluish } \\
\text { appearance }\end{array}$ \\
\hline B & $\begin{array}{l}\text { Rapidly forming with slightly less clear emulsion, } \\
\text { with a bluish-white appearance }\end{array}$ \\
\hline C & Fine milky emulsion \\
\hline $\mathrm{D}$ & $\begin{array}{l}\text { Slow to emulsify, dull, greyish white emulsion } \\
\text { having a slightly oily appearance }\end{array}$ \\
\hline $\mathrm{E}$ & $\begin{array}{l}\text { Poor or minimal emulsification with large oil } \\
\text { droplets on the surface }\end{array}$ \\
\hline
\end{tabular}

Robustness to dilution test - Robustness tests were carried out by diluting $1 \mathrm{~mL}$ of each CLO-SNEDDS with $100 \mathrm{~mL}$ of distilled water, $0.1 \mathrm{~N} \mathrm{HCl}$, and phosphate buffer $\mathrm{pH}$ 6.8. The mixtures were stirred using a magnetic stirrer and then stored for 24 hours to observe any physical change of system, including phase separation and precipitation ${ }^{21,22}$.

Determination of droplet size and polydispersity index Droplet size and polydispersity index were determined using a PSA. The test was carried out on the diluted CLOSNEDDS. A total of $100 \mu$ Lof CLO-SNEDDS was diluted with $50 \mathrm{~mL}$ of distilled water ${ }^{23}$.

Thermodynamic stability study - The stability was evaluated by centrifugation, a heating-cooling cycle, and a freeze-thaw cycle. Centrifugation tests were carried out at 3,500 RPM for 30 minutes. At heating cooling tests, CLO-SNEDDS were stored at two different temperatures $\left(45\right.$ and $\left.4^{\circ} \mathrm{C}\right)$. The tests were carried out in three cycles with storage at each temperature for not less than 48 hours. The freeze-thaw tests were carried out at two different temperatures: -21 and $25^{\circ} \mathrm{C}$, conducted for three cycles with storage at each temperature for not less than 48 hours $^{24}$.

\section{RESULTS AND DISCUSSION}

The SNEDDS was known to be one of the nano-based drug delivery systems suitable for the delivery of hydrophilic or lipophilic compounds. The CLO delivery in SNEDDS was expected to increase its dissolution, absorption, and bioavailability. The SNEDDS was prepared by mixing oil, surfactants, and cosurfactants without adding water, so SNEDDS was also known as a preconcentrated or anhydrous form of nanoemulsion ${ }^{13}$. The SNEDDS would form a nanoemulsion system spontaneously by gastrointestinal (GI) peristaltic. Miscibility of oil with surfactants and cosurfactants was important for the effectiveness of SNEDDS formation. The result showed that CLO has good miscibility property with Cremophor ${ }^{\circledR R H}-40$ and PEG 400. Surfactants and cosurfactants in the nanoemulsion were used to form a good and flexible interfacial film and decrease surface tension value to almost zero and support the spontaneous formation of nano globules ${ }^{25}$, as shown in Table II.

Table II. Result of CLO miscibility study

\begin{tabular}{clc}
\hline Type & \multicolumn{1}{c}{ Substance } & Ratio Miscibility \\
\hline Surfactant & Tween 80 & $1: 6$ \\
& Cremophor $®$ RH-40 & $1: 5$ \\
Cosurfactant & PEG 400 & $1: 4$ \\
& Propylene glycol & $1: 6$ \\
& Trancutol & $1: 7$ \\
\hline
\end{tabular}

The first step of the optimization formula was to determine the optimum ratio of the surfactant and the cosurfactant. Surfactants and cosurfactants used were Cremophor ${ }^{\circledR R H}-40$ and PEG 400. The percent 
transmittance test was used as the initial screening method to select the optimum ratio of surfactants and cosurfactants. The result showed that formula F2 (2: 1) had a percent transmittance value closest to $100 \%$, as shown in Table III. Therefore, the $2: 1$ ratio of surfactant and cosurfactant was used for the following research step.

Table III. Optimization result of ratio surfactant and

\begin{tabular}{cccc}
\multicolumn{4}{c}{ cosurfactant } \\
\hline Formula & Oil:Smix & S:CoS & \%transmittance \\
\hline F1 & $1: 9$ & $3: 1$ & $98.00 \pm 0.01$ \\
F2 & $1: 9$ & $2: 1$ & $99.60 \pm 0.06$ \\
F3 & $1: 9$ & $3: 2$ & $98.70 \pm 0.26$ \\
\hline
\end{tabular}

The next step was carried out to determine the optimum ratio of oil and smix using the percent transmittance test as an initial screening. The result showed that F2A, F2B, F2C, F2D, and F2E meet the percent transmittance requirement for SNEDDS (>90\%), as shown in Table IV $^{26}$. Therefore, the five formulas of CLO-SNEDDS were continued for further evaluation.

Table IV. Optimization result of ratio oil and smix

\begin{tabular}{cccc}
\hline Formula & Oil:Smix & S:CoS & \%transmittance \\
\hline F2A & $1: 9$ & $2: 1$ & $99.60 \pm 0.06$ \\
F2B & $1: 8$ & $2: 1$ & $98.80 \pm 0.05$ \\
F2C & $1: 7$ & $2: 1$ & $97.53 \pm 0.32$ \\
F2D & $1: 6$ & $2: 1$ & $97.90 \pm 0.85$ \\
F2E & $1: 5$ & $2: 1$ & $95.76 \pm 0.25$ \\
F2F & $1: 4$ & $2: 1$ & $39.00 \pm 3.21$ \\
\hline
\end{tabular}

Dispersibility tests, robustness tests, and thermodynamic stability tests were carried out on F2A, F2B, F2C, F2D, and F2E, as shown in Table V. The objective of dispersibility tests was to determine the ability of SNEDDS to disperse entirely and quickly when subjected to dilution under mild agitation. The test was carried out by visual observation, and then the grade was determined according to Table I. The SNEDDS preparations must exhibit grade $\mathrm{A}$ and $\mathrm{B}$ characteristics on the dispersibility test. The CLO-SNEDDS (F2A-F2E) could quickly produce a clear emulsion (nanoemulsion) system when diluted in water so that it was categorized as grade A in the dispersibility test. The ability of SNEDDS to form nanoemulsion spontaneously when diluted in water occurs due to the presence of surfactants and cosurfactants that were capable of forming an interfacial layer in the nano globules system ${ }^{27}$.

The purpose of the robustness test was to determine the system's stability after the SNEDDS preparation is diluted in three types of solvents with different $\mathrm{pH}$ values, like in the digestive tract conditions. The solvents used were distilled water medium, $\mathrm{HCl} 0.1 \mathrm{~N}$ (stomach condition), and a phosphate buffer pH6.8 (small intestine condition). The results showed that CLO-SNEDDS was able to form a stable system after dilution, using the three types of solvents, characterized by the absence of phase separation and precipitation ${ }^{28}$.

The subsequent study was the thermodynamic stability test, carried out by three types of tests (centrifugation, heating cooling, and freeze-thaw). The results showed that CLO-SNEDDS (F2A, F2B, F2C, and F2D) had good stability marked by not occurring phase separation and sedimentation. This indicates that the CLO-SNEDDS (F2A, F2B, F2C, and F2D) had good kinetic and thermodynamic stability. The F2E formula shows instability in thermodynamic testing, which could occur because the number of surfactants and cosurfactants was insufficient to form a stable nanoemulsion system ${ }^{29}$.

Based on the dispersibility, robustness, and thermodynamic test, it could be concluded that CLOSNEDDS (F2A, F2B, F2C, and F2D) had good physical characteristics. Formula F2D with a ratio of oil and smix $1: 6$ was chosen as the final formula (Figure 2). The formula was chosen because it still produces SNEDDS with good physical characteristics, with the least amount of smix. This was expected can minimize the risk of negative effects of surfactants and cosurfactants for oral administration. 
Table V. Dispersibility, robustness, and thermodynamic stability tests results

\begin{tabular}{|c|c|c|c|c|c|c|}
\hline & Evaluation & F2A & F2B & F2C & F2D & F2E \\
\hline \multirow[t]{3}{*}{ Dispersibility } & Emulsification time (s) & $35.30 \pm 0.55$ & $33.83 \pm 0.32$ & $34.30 \pm 0.61$ & $35.86 \pm 2.52$ & $43.73 \pm 0.38$ \\
\hline & Appearance & Clear & Clear & Clear & Clear & Clear \\
\hline & Grade & $\mathrm{A}$ & $\mathrm{A}$ & $\mathrm{A}$ & $\mathrm{A}$ & $\mathrm{A}$ \\
\hline \multirow[t]{3}{*}{ Robustness } & Distilled water & Stable & Stable & Stable & Stable & Stable \\
\hline & $\mathrm{HCl} 0.1 \mathrm{~N}$ & Stable & Stable & Stable & Stable & Stable \\
\hline & Phosphate buffer pH6.8 & Stable & Stable & Stable & Stable & Stable \\
\hline \multirow[t]{4}{*}{ Thermodynamic } & Centrifugation & Stable & Stable & Stable & Stable & Stable \\
\hline & Heating cooling & Stable & Stable & Stable & Stable & Stable \\
\hline & Freeze-thaw & Stable & Stable & Stable & Stable & Unstable \\
\hline & Conclusion & Qualify & Qualify & Qualify & Qualify & Unqualify \\
\hline
\end{tabular}

The F2D formula was further evaluated by determining an average of globules size and polydispersity index (PDI) of the nanoemulsion system. The results of globule size analysis using a particle size analyzer showed that CLO-SNEDDS (F2D) was able to form a nanoemulsion system after dilution with a globule size of $125 \mathrm{~nm}$ and a PDI value of 0.515 . These results followed the globule size requirements for SNEDDS $(20-200 \mathrm{~nm})$ and PDI of $<0.730$.

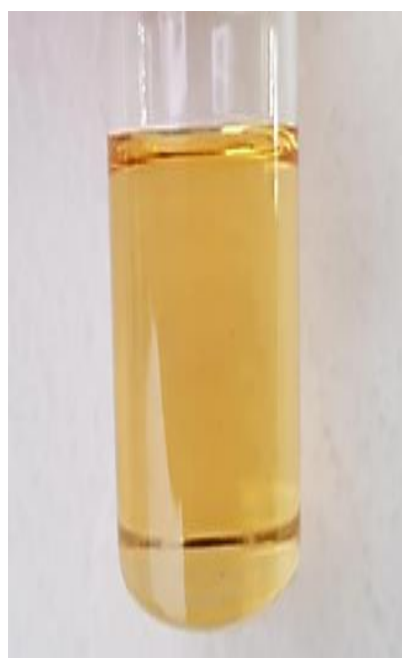

Figure 2. The CLO-SNEDDS Formula F2D

\section{CONCLUSION}

The CLO-SNEDDS preparation with the ratio of a surfactant and cosurfactant $(2: 1)$ and a ratio of oil and smix $(1: 6)$ had good physical characteristics based on \%transmittance, dispersibility, robustness, and thermodynamic stability studies. The CLO-SNEDDS (F2D) preparation was able to produce a nanoemulsion system after dilution with a globule size of $125 \mathrm{~nm}$ and a PDI of 0.515 .

\section{ACKNOWLEDGMENT}

We would like to thank the research Centre of Universitas Islam Bandung for funding this research.

\section{AUTHORS' CONTRIBUTION}

Sani Ega Priani: Conceptualization, supervisor, methodology, data curation, formal analysis, writing original draft. Desti Puspa Rahayu: Methodology, investigation, formal analysis, administration. Indra Topik Maulana: Conceptualization, data curation, supervisor.

\section{DATA AVAILABILITY}

All data are available from the authors.

\section{CONFLICT OF INTEREST}

The authors declare no conflict of interest.

\section{REFERENCES}

1. Lentjes MAH, Mulligan AA, Welch AA, Bhaniani A, Luben RN, Khaw KT. Contribution of cod liver oilrelated nutrients (vitamins A, D, E and eicosapentaenoic acid and docosahexaenoic acid) to daily nutrient intake and their associations with plasma concentrations in the EPIC-Norfolk cohort. J Hum Nutr Diet. 2015;28(5):568-82. doi:10.1111/jhn.12271

2. Innes JK, Calder PC. Marine Omega-3 (N-3) Fatty Acids for Cardiovascular Health: An Update for 2020. Int J Mol Sci. 2020;21(4):1362. doi:10.3390/ijms21041362 
3. Innes JK, Calder PC. The Differential Effects of Eicosapentaenoic Acid and Docosahexaenoic Acid on Cardiometabolic Risk Factors: A Systematic Review. Int J Mol Sci. 2018;19(2):532. doi:10.3390/ijms19020532

4. Tørris C, Småstuen MC, Molin M. Nutrients in Fish and Possible Associations with Cardiovascular Disease Risk Factors in Metabolic Syndrome. Nutrients. 2018;10(7):952. doi:10.3390/nu10070952

5. Yang S, Lin R, Si L, Li Z, Jian W, Yu Q et al. Cod-Liver Oil Improves Metabolic Indices and hs-CRP Levels in Gestational Diabetes Mellitus Patients: A DoubleBlind Randomized Controlled Trial. J Diabetes Res. 2019;2019:7074042. doi:10.1155/2019/7074042

6. Salama MF, Abbas A, Darweish MM, El-Hawwary AA, Al-Gayyar MMH. Hepatoprotective effects of cod liver oil against sodium nitrite toxicity in rats. Pharm Biol. 2013;51(11):1435-43. doi:10.3109/13880209.2013.796564

7. Lauritzen L, Brambilla P, Mazzocchi A, Harsløf LBS, Ciappolino V, Agostoni C. DHA Effects in Brain Development and Function. Nutrients. 2016;8(1):6. doi:10.3390/nu8010006

8. Rathod G, Kairam N. Preparation of omega 3 rich oral supplement using dairy and non-dairy based ingredients. J Food Sci Technol. 2018;55(2):760-6. doi:10.1007/s13197-017-2988-7

9. Gulotta A, Saberi AH, Nicoli MC, McClements DJ. Nanoemulsion-based delivery systems for polyunsaturated $(\omega-3)$ oils: formation using a spontaneous emulsification method. J Agric Food Chem. 2014;62(7):1720-5. doi:10.1021/jf4054808

10. Walker RM, Gumus CE, Decker EA, McClements DJ. Improvements in the formation and stability of fish oil-in-water nanoemulsions using carrier oils: MCT, thyme oil, \& lemon oil. J Food Eng. 2017;211:60-8. doi:10.1016/j.jfoodeng.2017.05.004

11. García-Márquez E, Higuera-Ciapara I, EspinosaAndrew H. Design of fish oil-in-water nanoemulsion by microfluidization. Innov Food Sci Emerg Technol. 2017;40:87-91. doi:10.1016/j.ifset.2016.11.007

12. Jaiswal M, Dudhe R, Sharma PK. Nanoemulsion: an advanced mode of drug delivery system. 3 Biotech. 2015;5(2):123-7. doi:10.1007/s13205-014-0214-0

13. Yin HF, Yin CM, Ouyang T, SunSD, Chen WG, Yang $\mathrm{XL}$, et al. Self-Nanoemulsifying Drug Delivery
System of Genkwanin: A Novel Approach for AntiColitis-Associated Colorectal Cancer. Drug Des Devel Ther. 2021;15:557-76. doi:10.2147/DDDT.S292417

14. Shahba AAW, Mohsin K, Alanazi FK. Novel SelfNanoemulsifying Drug Delivery Systems (SNEDDS) for Oral Delivery of Cinnarizine: Design, Optimization, and In-Vitro Assessment. AAPS PharmSciTech. 2012;13(3):967-77. doi:10.1208/s12249-012-9821-4

15. Ujilestari $T$, Martien R, Ariyadi B, Dono ND, Zuprizal. Self-nanoemulsifying drug delivery system (SNEDDS) of Amomum compactum essential oil: Design, formulation, and characterization. J Appl Pharm Sci. 2018;8(6):14-21. doi:10.7324/JAPS.2018.8603

16. Zhao Y, Wang C, Chow AHL, Ren K, Gong T, Zhang $Z$, et al. Self-nanoemulsifying drug delivery system (SNEDDS) for oral delivery of Zedoary essential oil: formulation and bioavailability studies. Int J Pharm. 2010;383(1-2):170-7. doi:10.1016/j.jpharm.2009.08.035

17. Priani SE, Somantri SY, Aryani R. Formulasi dan Karakterisasi SNEDDS (Self Nanoemulsifying Drug Delivery System) Mengandung Minyak Jintan Hitam dan Minyak Zaitun. JSFK (Jurnal Sains Farmasi \& Klinis). 2020;7(1):31-8. doi:10.25077/jsfk.7.1.31-38.2020

18. Patel J, Patel A, Raval M, Sheth N. Formulation and development of a self-nanoemulsifying drug delivery system of irbesartan. J Adv Pharm Technol Res. 2011;2(1):9-16. doi:10.4103/2231-4040.79799

19. Ke Z, Hou X, Jia XB. Design and optimization of selfnanoemulsifying drug delivery systems for improved bioavailability of cyclovirobuxine D. Drug Des Devel Ther. 2016;10:2049-60. doi:10.2147/dddt.s106356

20. Savale SK. A Review - Self Nanoemulsifying Drug Delivery System (SNEDDS). Int J Res Pharm Nanosci. 2015;4(6):385-97.

21. Ali HH,Hussein AA. Oral solid self-nanoemulsifying drug delivery systems of candesartan citexetil: formulation, characterization and in vitro drug release studies. AAPS Open. 2017;3:6. doi:10.1186/s41120-017-0015-8

22. Priani SE, Nurrayyan N, Darusman F. Formulation self nano emulsifying drug delivery system glimepiride using oleic acid as oil phase. 
Pharmaciana Jurnal Kefarmasian. 2017;7(2):267-76. doi:10.12928/pharmaciana.v7i2.7387

23. Priani SE, Annisa A, Darma GCE. Dissolution enhancement of atorvastatin calcium by selfnanoemulsifying drug delivery system using cremophor RH 40 and Transcutol P as surfactants. Drug Invent Today. 2018;10(Special Issue 5):3768-72.

24. Syukri Y, Fitriani H, Pandapotan H, Nugroho BH. Formulation, Characterization and Stability of Ibuprofen-Loaded Self-Nano Emulsifying Drug Delivery System (SNEDDS). Indones J Pharm. 2019;30(2):105-13.

doi:10.14499/indonesianjpharm30iss2pp105-113

25. Baloch J,Sohail MF, Sarwar HS, Kiani MH, Khan GM, Jahan S, et al. Self-Nanoemulsifying Drug Delivery System (SNEDDS) for Improved Oral Bioavailability of Chlorpromazine: In Vitro and In Vivo Evaluation. Medicina. 2019;55(5):210. doi:10.3390/medicina55050210

26. Syukri Y, Martien R, Lukitaningsih E, Nugroho AE. Novel Self-Nano Emulsifying Drug Delivery System (SNEDDS) of andrographolide isolated from Andrographis paniculata Nees: Characterization, invitro and in-vivo assessment. J Drug Deliv Sci Technol. 2018;47:514-20. doi:10.1016/j.jddst.2018.06.014

27. Parmar K, Patel J, Sheth N. Self nano-emulsifying drug delivery system for Embelin: Design, characterization and in-vitro studies. Asian J Pharm Sci. 2015;10(5):396-404. doi:10.1016/j.ajps.2015.04.006

28. Winarti L. Formulation of Self-Nanoemulsifying Drug Delivery System of Bovine Serum Albumin Using HLB (Hydrophilic-Lypophilic Balance) Approach. Indones J Pharm. 2016;27(3):117-27. doi:10.14499/indonesianjpharm27iss3pp117

29. Tong Y, Wang Y, Yang M, Yang J, Chen L, Chu X, et al. Systematic Development of Self-Nanoemulsifying Liquisolid Tablets to Improve the Dissolution and Oral Bioavailability of an Oily Drug, Vitamin K1. Pharmaceutics. 2018;10(3):96. doi:10.3390/pharmaceutics10030096

30. Eid AM, Elmarzugi NA, Jaradat NA. Influence of sonication and in vitro evaluation of nifedipine selfnanoemulsifying drug delivery system. Braz J Pharm Sci. 2019;55:e17497. doi:10.1590/s217597902019000217497 